\title{
The pipeline transport of high density slurries - a historical review of past mistakes, lessons learned and current technologies
}

\author{
A.J.C. Paterson Paterson \& Cooke, South Africa
}

\begin{abstract}
There is a great deal of misinformation in the industry on pumping high density, viscous slurries. These misconceptions become "accepted truths" as time goes on and at best hinder, and at worst stop, the implementation of appropriate technology. Unfortunately the root of these misconceptions is often due to experiences gained on poorly understood, designed or implemented systems. Advances in a technology can only be realised by accepting that the mistakes of the past can be rectified and learned from. Unfortunately this does not readily happen in an industry that is resistant to change. The objective of this paper is to address these issues by tracing the historical development of high density pumping and why the problems of the past are not necessarily the same problems of today. It is accepted that many of the fundamental problems cannot be resolved, and continued improvements in ore processing will mean that new challenges will arise. However, there is a better understanding of how to deal with the issues practically by using the latest developments in pump and pipeline technology.
\end{abstract}

\section{Introduction}

Slurry pumping is a well established technology, to the extent that it is now widely used as the preferred method of transporting mineral concentrates. Long distance slurry pipeline systems are widely used and generally have an excellent track record of high availability, excellent safety and favourable economics when compared to conventional bulk transport systems. However, pumping mineral concentrates hundreds of kilometres is seen to be less challenging than pumping paste and thickened tailings a few kilometres. Despite the many successes of slurry pipelines using high pressure pumps, there is a general reluctance within the waste disposal engineering community to embrace new technology. Generally the excuses given are high system costs, potentially unsafe high pipeline pressures, and complex maintenance that is not suited to a mining operation. Obviously costs are always relevant and site specific, but good engineering and understanding of what is being pumped deals with, and resolves, any excuses given for technical reservations.

This seminar paper will deal with some of the common reasons why new slurry pipeline technology for thickened tailings disposal systems is not adopted, and presents the case for embracing new technology when it is appropriate. As environmental pressures increase, and intelligent water usage becomes crucial, operations that fail to deal with such issues are at risk of losing their 'moral' licence to operate as public opinion can turn swiftly.

\section{Technology acceptance}

It takes time for new technologies to be adopted as common practice, and this seems to be especially true of paste and thickened tailings disposal. This may be due to many reasons, such as challenges to conventional wisdom, resistance to change, scepticism of claims, and finally proof of success that takes time due to a slow uptake of the technology. This is typical of the well known technology diffusion curve that shows that degree of acceptance can be broken down as follows (Figure 1):

- Innovators of the technology who create awareness, representing a small percentage, less than 2.5\%.

- Early adopters who commit to the technology, representing about $13 \%$.

- Early and late majority who prove the technology through widespread use, representing $64 \%$ of users. 
- Hesitant accepters, the last $16 \%$, who finally accept the change and adopt the technology.

Paste and thickened tailings disposal as a complete solution is probably now just being accepted by the early majority, only having been properly employed by a few early adopters worldwide. Regionally some countries are showing a higher acceptance rate than others, but the vast majority of new projects are developed using conventional technology with step wise adoption of the new technologies.

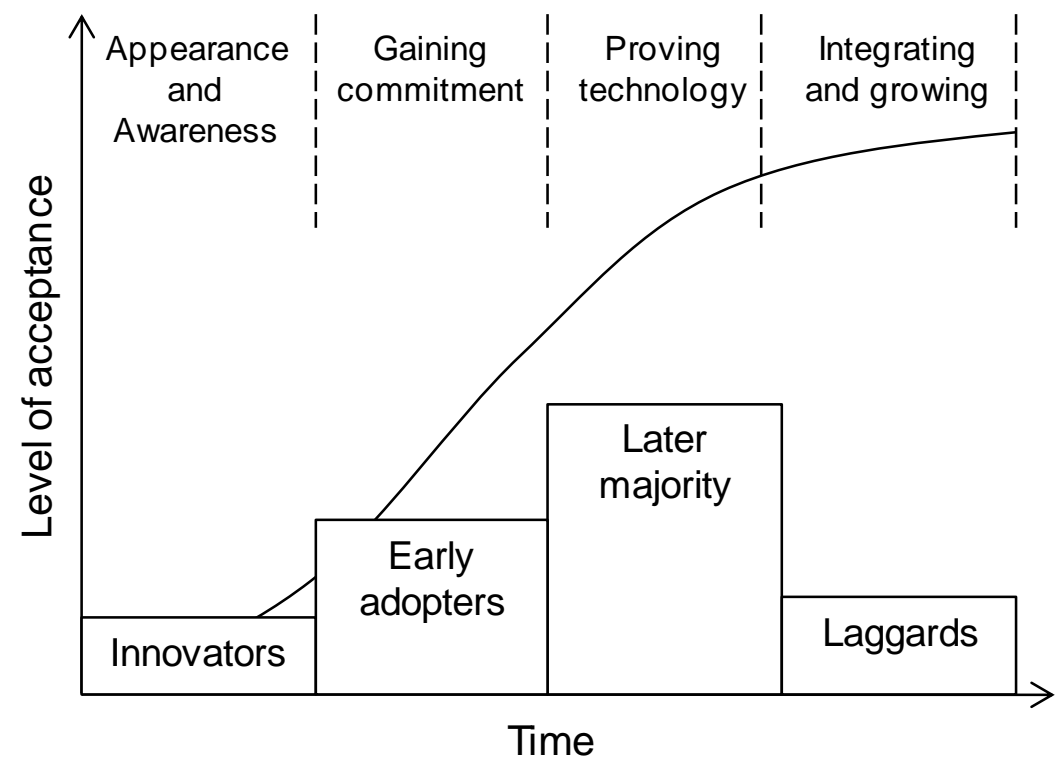

Figure 1 Technology diffusion (Rogers, 1962)

It is not the aim of this paper to position paste and thickened tailings disposal as a completely accepted technology, but to demonstrate that the current state of the art in pump and pipeline technology is based on a long learning curve and must not be seen as a barrier to implementing a total solution.

\subsection{Early setbacks}

Early slurry pipeline innovation was dealt a serious setback in the United States by the railroad lobby, and it is a story worth recounting. Arguably modern slurry pipeline engineering began with the first major long distance ore pipeline system for Ohio's Consolidation Coal that was $172 \mathrm{~km}$ and pumped 1.3 MT of coal per year. Commissioned in 1957, it operated for about six years and proved to be a cheap and viable alternative bulk transport method. This forced the railways to reduce tariffs and the system was eventually shut down. The project paved the way for President Kennedy to promote the idea of long distance coal pipelines in 1962 to help the ailing coal industry. "How slurry pipelines save consumer dollars" is one of the headlines from early Kennedy brochures. In 1964 Peabody Mine negotiated a controversial agreement with the Navajo and Hopi tribes, allowing the company mineral rights and use of an underground aquifer. Having the required water meant that a coal slurry pipeline could be considered and the Black Mesa coal slurry pipeline was constructed. Since the pipeline began operating in 1970 until it was shut down in 2005 there was continual environmental pressure regarding the ground water usage and its effect on the local communities. Nonetheless the pipeline itself operated very successfully, pumping 4.8 MT per year of coal from the mine to the Mohave Generating Station in Southern Nevada, a distance of $435 \mathrm{~km}$.

Following the commissioning of the Black Mesa Project, Energy Transportation Systems Inc. was formed in 1973 to develop, build and operate coal slurry pipelines that would supply coal to various States in the US. Some 2,250 km of pipeline were planned, through Wyoming, Colorado, Kansas, Oklahoma and Arkansas transporting up to 30 MT per year. This clearly represented a major threat to the well entrenched railway network. Ultimately, the project was stopped in the late 1970s because of activist railroad lobbying that barred slurry pipelines from crossing railway servitudes, effectively blocking long distance pipelines in the USA. This was a major blow to the future of the slurry pipelines because had such a project gone ahead, slurry pipeline technology would have reached its current level many years earlier. 


\section{Early innovators}

\subsection{High concentration non-Newtonian slurry flow development}

After coal pumping pioneered the way for conventional slurry systems, the benefits of pumping high concentration mixtures became apparent early on. In the laboratory it was possible to pump viscous coal slurries at high solids concentrations and low transport velocities. A great deal of research was done in the coal mining industry, first pioneered by Elliott and Gliddon (1970), who identified the stabilised flow concept whereby the larger solid particles are supported by the yield stress of the high-concentration fines carrier or vehicle portion of the slurry. The term "stab-flo" was first used by Lawler et al. (1978) to describe these particular coal-water slurries. Viscometer tests indicated the feasibility of transporting coal slurries at the so-called stab-flo condition. An economic evaluation comparing conventional coal slurry transport (i.e. heterogeneous low concentration) to stab-flo indicated the considerable advantages of high concentration pumping technology. The stab-flo approach yielded the most potential in terms of economic viability as a new alternative to the standardised or conventionally accepted methods of coal transport. Duckworth and Pullum (1983) performed a series of tests on the transport of coarse coal at high concentrations and concluded that the stab-flo condition was possible if the vehicle or fluid carrier is non-Newtonian and has a yield stress large enough to support the top size particle (the slurry yield stress must be greater than the submerged weight of the largest particle in the slurry).

The development of stab-flo led to the application of this technology to other mineral slurry types in the mining industry, such as paste and thickened tailings. The predominant features of this flow regime are generally reported as:

1. Large particles are suspended by the viscosity and yield stress of the fine particle/water mixture.

2. There is a predominantly high percentage of fine particles in the slurry.

3. Uniform concentration and velocity profiles.

4. Uniform, well graded particle size distribution.

5. Generally non-Newtonian and homogeneous.

Unfortunately some of these assumptions and benefits originally espoused, turned out to be incorrect. In particular the seemingly obvious assumption those slurries that appear to be stable in the static condition will not settle in a pipeline.

\subsection{Paste backfill}

Deep level mining presented itself as the next arena for pushing the limits of pumping as mines required backfill for underground support. The traditional hydraulic backfill systems that were widely used in the 1970s and 1980s had many shortcomings; not least the excessive amount of water being put back into the mine. The Bad Grund Mine in Germany was one of the first operations to use a high density backfill in 1979 and may operations soon followed. In 1988 a South African mine (Webbstock et al., 1993) used vacuum filtered full plant metallurgical tailings as backfill, which would now be termed paste fill. Arguably the bulk of the development in paste fill was done in Canada by Inco Limited that led to the first Canadian paste fill plant at Garson Mine in 1994. In Australia, Henty Mine was the first to use paste fill successfully in 1997, and other mines began to follow.

Early paste backfill pipe flow tests were conducted using simple re-circulating loops driven by concrete piston pumps. These flow loops delivered typical data as shown in Figure 2. Clearly the flow behaviour of these materials is laminar at high solids concentrations. When these systems were installed correctly settling of solids in the horizontal pipelines did not seem to be a problem.

Typical of many industries, communication and cross-pollination of technology does not happen as often as it should. The work done on paste backfill was specifically focussed on finding a solution for better underground support, and the pipeline test work was merely done to show that the material could be pumped and transported. The fact that this material did not present a pumping challenge was not considered unusual as the test experience clearly demonstrated that these viscous materials could be transported by pipeline, 
albeit with high friction losses. This was clearly different from what others had experienced when pumping laminar flow mixtures. It would be some time before these differences were understood.

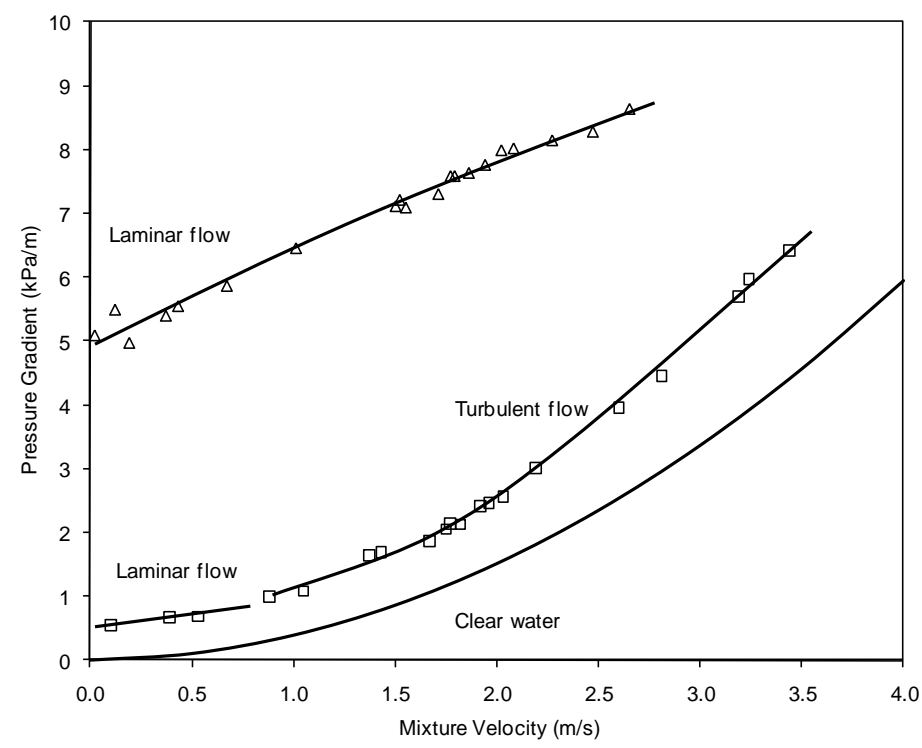

Figure 2 Typical measured data from a paste backfill re-circulating loop

\subsection{Paste thickeners}

The industry is well aware of the original work done by E. Robinsky at Falconbridge's Kidd Creek Mine in Timmins, Ontario, that was the first operation to adopt the principles of a centrally thickened discharge tailings disposal system. It was a concept ahead of its time, and unfortunately current state-of-the-art meant that the full benefits of the system were not readily apparent, due to the inability to produce a consistently dewatered material.

The challenges associated with the disposal of bauxite residue resulted in the development of dewatering technology by Alcoa in the 1970s (Doucet and Paradis, 2010) that first paved the way for high concentration residue disposal. In particular, the development of the Alcan paste thickener meant that dewatering to high solids concentrations could be done without the need for filters. Paste thickeners are now widely used by the mineral industry in a variety of applications, and are well understood and are accepted as a proven technology.

\subsection{Pumping and pipeline systems}

Paste backfill plants usually deliver the paste directly to the underground stopes using vertical boreholes. These boreholes provide sufficient gravity head to transport the material horizontally underground. A typical example at Cleveland Potash (Fehrsen et al., 2007) transports potash and brine backfill to the stopes $11 \mathrm{~km}$ away from the shaft. This system uses high pressure energy dissipaters, such as those shown in Figure 3, to ensure that the pipeline operates fully pressurised so as to eliminate slack flow.

Where overland pumping was needed, early paste backfill systems used concrete type piston pumps. These pumps are capable of pumping fine and coarse viscous materials, and for low volume applications remain a good choice. Hydraulically activated poppet valves are used for finer slurries, and coarser slurries are pumped by replacing the valves with a swing tube valve arrangement. These pumps have typical flow rate capacities of up to $280 \mathrm{~m}^{3} / \mathrm{h}$ at a discharge pressure of 10-13 MPa. 


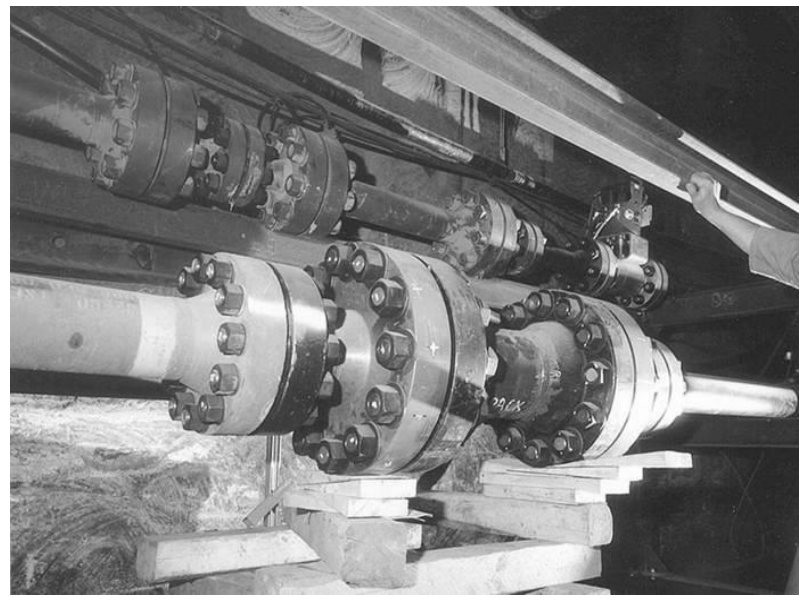

Figure 3 High pressure energy dissipaters to control flow rate in a paste fill system

To pump larger volumes at higher pressures, piston diaphragm pumps are used for paste and thickened tailings systems. The limitation on these pumps is usually the maximum drive capacity that can be installed on a single pump. For high pressure applications and large flow rates, this means that several pumps in parallel are needed.

\subsection{Acceptance levels}

These innovative developments have made it possible to dewater slurries to high solids concentrations, and paste backfill has become integral to many underground mining operations. Why there is not the same level of acceptance for surface pumping of thickened and paste tailings is mostly due to the following preparation and pumping issues:

- perceived complexity of operation of preparation plant and pumping equipment

- poor understanding of pipeline flow behaviour at intermediate solids concentrations

- initial high capital costs associated with high pressure pumps.

Deposition issues are generally tailored to meet the local site conditions.

\section{$4 \quad$ Early adopters}

\subsection{Further setbacks}

The early innovative work showed tremendous promise and application for high concentration nonNewtonian slurry transport, however, expectation exceeded understanding and some serious setbacks occurred. The most fundamental error is the assumption that materials that are apparently homogeneous in a static, or quiescent condition, will not settle in the pipeline. Certainly this appeared to be true when pumping paste backfill, but under other conditions pipeline flow was not so simple, as demonstrated by the following two well known operations.

\subsubsection{Stabilised coal transport}

The most dramatic example of this was the application of stab-flo technology used to design and build the $258 \mathrm{~km}$ Belovo-Novosibirsk coal slurry pipeline. This $530 \mathrm{~mm}$ pipeline was designed to transport 3 million dry tonnes of coal per year. The design slurry yield stress was low, 11-13 Pa, and the pipeline was designed to operate at $0.7-0.9 \mathrm{~m} / \mathrm{s}$. During commissioning only 300,000 tonnes of coal were transported and ongoing operational problems and blockages were frequent, resulting in the closure of the pipeline after less than four years of operation (Cowper et al., 2010). It is important to note that during commissioning, the flow rates were much lower than the design, and the system operated at velocities of $0.1 \mathrm{~m} / \mathrm{s}$, probably on the assumption it would be safe to do so as no settling was expected during laminar flow. 


\subsubsection{Limestone transport}

During early operation of the $92 \mathrm{~km}$ long, $252 \mathrm{~mm}$ diameter pipeline, limestone slurry pipeline in Rugby, England, it was observed that the pipeline pressure gradient increased slowly, and that there was a discrepancy between the solids concentration entering and leaving the pipeline (Cooke, 2002). Analysis done by the mine at the time showed that the coarser particles were settling in the pipeline and accumulating on the invert. The pipeline had to be regularly flushed with water to maintain the pump station discharge pressure below $10 \mathrm{MPa}$. The pipeline operated at a velocity of $1.1 \mathrm{~m} / \mathrm{s}$, and the critical transition velocity between laminar and turbulent flow was also estimated at $1.1 \mathrm{~m} / \mathrm{s}$ (Wasp, 1999). Small changes in the slurry properties would have resulted in unstable operation as the flow regime varied from laminar to turbulent flow.

The Trinidad limestone pipeline pumped limestone with a yield stress of $26 \mathrm{~Pa}$ a distance of $10 \mathrm{~km}$. Solids settling on the pipeline invert caused pump station discharge pressures to rise, and the system had to be flushed using pigs every two days. The system operated at a velocity of $2 \mathrm{~m} / \mathrm{s}$, well below the estimated critical velocity of $3.9 \mathrm{~m} / \mathrm{s}$ (Wasp, 1999).

These early setbacks led many in the long distance piping industry to believe that operating in laminar flow regimes was not feasible.

\subsection{Early successes}

As mentioned, paste backfill systems were shown to operate without settling at low velocities, and the mining industry began to investigate thickened and paste tailings for surface disposal. Many of the early thickened tailings systems chose to operate at densities that could utilise low pressure centrifugal pumps. This meant that the flow regime was mostly turbulent, and problems associated with laminar flow operation did not occur. This was perhaps not because there was an awareness of the issues associated with laminar flow, and was possibly more due to a cautious approach to adopting a new technology. As these early thickened tailings systems, such as Mt Keith and Peak Gold Mine, showed that there were distinct benefits to depositing at increased solids concentration, interest grew in pumping at higher densities. At high densities, the flow behaviour is very dependent on the tailings properties and as solids concentration increases these effects are more pronounced. In particular, materials with a high percentage of fine particles, or high clay contents, become significantly more viscous.

\subsubsection{Red mud disposal, Australia}

The importance of understanding the flow behaviour and rheology of thickened tailings was highlighted by the work done in Australia on the disposal of bauxite residue. The pumping systems at Kwinana refinery use both centrifugal and positive displacement pumps that are selected depending on the beaching requirements and pipeline lengths. As centrifugal pumps shear the material more than the positive displacement pumps, the viscosity is reduced and the deposition is affected. In order to obtain proper drying and stacking of the residue, regardless of the shear history, a minimum yield stress was required at the deposition site. The slump cone proved to be a simple means to estimate the change in slurry yield stress (Pashias et al., 1996) of the material deposited onto the beach. Boger et al. (2002) demonstrated that the disposal requirements should be the starting point for estimating the upstream pipeline, pumping and preparation systems as the change in flow parameters due to shear in the pump and pipeline have a significant effect on the beaching properties of the material.

\subsubsection{Kimberley Combined Treatment Plant, South Africa}

Since 2003 the De Beers Combined Treatment Plant (CTP) has been depositing high density thickened slurry using the central discharge placement philosophy. The system, described in detail by Houman and Johnson (2003) and Johnson and Vietti (2003), comprises four paste thickeners that produce a high density underflow that is pumped using three piston diaphragm pumps to the disposal site $5.5 \mathrm{~km}$ away. The system operates in laminar flow and blockages during commissioning and early operation occurred when excessive coarse material entered the pipeline. The yield stress of the slurry being pumped varies considerably from approximately 50-125 Pa, depending on the shear history of the material and the particle size distribution and clay fraction. The system pumps a mixture of coarse and fine material, with a combined top size of 
$1 \mathrm{~mm}$. This coarse fraction remains suspended in the mixture when left to settle in a quiescent state. However, when pumping the slurry flow behaviour changes during the pipeline transit time due to a combination of the effect of shear and settling of the coarser particles on the pipeline invert. Although particles settle on the invert, they continue to move through the pipeline in a stratified laminar flow regime (Pullum et al., 2004).

Using a paste disposal system resulted in an overall water consumption of approximately $0.4 \mathrm{~m}^{3} / \mathrm{t}$, which is considerably better than conventional kimberlite tailings disposal systems that consume 0.8 to $1.0 \mathrm{~m}^{3} / \mathrm{t}$.

\subsubsection{Osborne Mine, Australia}

In 2003 Osborne Mine in northwestern Queensland converted their tailings disposal system to a thickened tailings deposition site using and advancing cone strategy (McPhail and Brent, 2007). The system uses conventional centrifugal pumps as the slurry is not viscous and can be pumped at solids concentrations of up to $80 \%$ by mass, although normal operation is at approximately $65 \%$ by mass. Good control and operation of the system has meant that the beach angles are maintained and water savings greater than $40 \%$ have been achieved.

\section{$5 \quad$ Large scale adopters}

Based on the successes of early thickened and paste tailings deposition systems, there are several large projects underway that utilise this technology, but are yet to be commissioned. Two significant projects, Esperanza and Chinalco, are worth comparing as the pumping requirements are very different.

\subsection{Esperanza}

Esperanza is a copper-gold mine currently under construction in Chile's arid Antofagsta region. The mine will process approximately 100,000 tonnes of ore per day, and availability of water is a key issue. In order to mitigate the requirements for fresh water, the mine is using sea water for processing pumped $145 \mathrm{~km}$ from the coast to the mine site, and has adopted high density thickened tailings disposal technology. In August 2009 Esperanza was awarded the Avonni prize in Chile for the most innovative mining operation for these water saving initiatives, highlighting the importance being placed on such initiatives.

The paste tailings are very viscous with high yield stress and will be deposited from a central discharge area that is relatively close to the process plant. As the disposal site develops, the pumping distances will increase to a maximum of approximately $1 \mathrm{~km}$. Data from Luppnow and Moreno (2009) shows that the slurry yield stress varies from about $50 \mathrm{~Pa}$ at $66 \% \mathrm{~m}$ to $200 \mathrm{~Pa}$ at $70 \% \mathrm{~m}$.

As the pumping distances are relatively short, several centrifugal pumps in series, located in a single pump station at the thickeners, will be used to transport the thickened tailings in the large diameter pipeline. For the reported yield stress values the flow regime will be laminar.

\subsection{Chinalco}

Chinalco in Peru is currently developing the Toromocho Project that will process 117,000 tonnes per day of ore. This project is very similar to the Esperanza project and both will use high density thickened tailings, however, the pumping systems are very different. At Toromocho the thickened slurry needs to be pumped uphill a distance of approximately $4.7 \mathrm{~km}$. The tailings will be thickened using four $43 \mathrm{~m}$ diameter paste thickeners, and pumped to the disposal site. The required pump station discharge pressure requirement is $12 \mathrm{MPa}$. These pressures cannot be provided by large centrifugal pumps of this size that usually have casing limitations of $2.1 \mathrm{MPa}$, and in some instances up to $5 \mathrm{MPa}$. This means that three centrifugal pump stations would be needed, each spaced about $1.6 \mathrm{~km}$ apart. Positive displacement pumps can produce high pressures, but normally have limitations in the flow capacity.

Recent developments in drive technology now enable single pumps with drive capacities of up to 2,600 $\mathrm{kW}$ (van Rijswick et al., 2010), theoretically halving the number of piston diaphragm pumps needed. In the last decade the maximum hydraulic power per pump has more than doubled and this means fewer pumps can be used. P. Geraedts (written comm., 2010) predicts that by 2015 pumps with drives of up to 3 MW will be 
available, with the possibility of 4 MW drives. Figure 4 shows data from van Rijswick et al. (2010) and P. Geraedts (written comm., 2010) that show a similar steady increase in power capacity per pump.

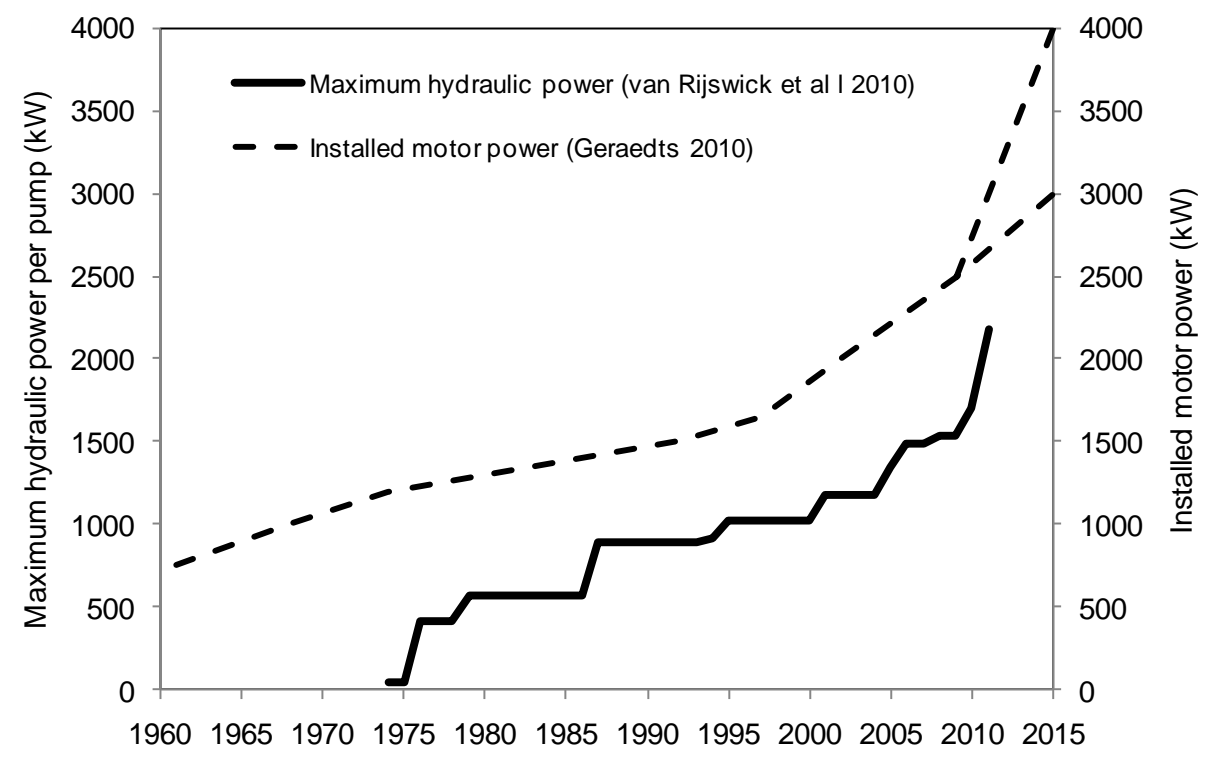

Figure 4 Historical increase in hydraulic power of piston diaphragm pumps after van Rijswick et al. (2010) (courtesy of Weir Minerals) and P. Geraedts (written comm., 2010) (courtesy of Aker Wirth)

Rayo and Fuentes (2009) reported on a study for a 230,000 tonne per day disposal facility for CodelcoChile's Talabre Mine that would need 25 positive displacement diaphragm pumps in parallel, each with 1.3 MW drives. Using pumps of this size at Chinalco would have meant a similar high number of pumps being needed, operating in parallel, to produce the required flow and pressure, however, new pump technology enabled Chinalco to use 10 large pumps in parallel (van Rijswick et al., 2010).

Technology advances such as this will provide impetus to the acceptance and use of thickened tailings disposal using positive displacement pumps.

\section{$6 \quad$ Proving the technology}

\subsection{Understanding the settling problems}

Laminar pipeline flow regimes historically were characterised by uniform flow with a symmetric concentration and velocity profile across the pipe section. In practice these sorts of flow regimes are exceedingly rare in mineral processes due to the coarse solids fraction. It is now known that a fraction of the particles settle on the pipe invert, resulting in stratified flow with an asymmetric concentration and velocity profile with either a stationary bed, or a sliding bed, shown in Figure 5.

Cooke (2002), Pullum (2007) and others have dealt with this problem in some detail. For non-Newtonian slurries in pipelines, the applied stress must be greater than the slurry yield stress for the material to flow. The yield stress determines the size of the sheared annulus and unsheared plug. As flow develops the viscosity of the fluid in the sheared annulus decreases relative to the particle, and settling of particles in this region occurs. As particles settle towards the invert the velocity profile changes from uniform to nonuniform, as the point of maximum velocity is no longer at the pipe centre and moves upwards. In doing so, the effective sheared annulus also moves upwards, and particles that were in the plug, are now exposed to local shear and begin to settle. 


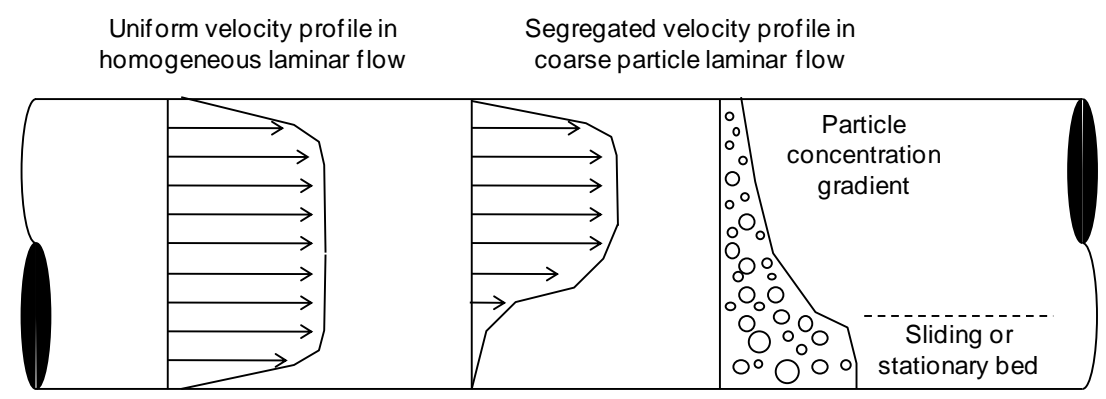

Figure 5 Flow regimes in laminar flow

Bearing this phenomenon in mind, it is interesting to compare some of the flow regimes of the examples presented, as shown in Table 1.

Table 1 Pipeline flow regimes for selected systems

\begin{tabular}{lccccc}
\hline System and Material & $\begin{array}{c}\text { \% Solids by } \\
\text { Mass }\end{array}$ & $\begin{array}{c}\text { Flow } \\
\text { Regime }\end{array}$ & $\begin{array}{c}\text { Top Size } \\
\text { Particle } \\
(\mathbf{m m})\end{array}$ & $\begin{array}{c}\text { Major } \\
\text { Blockage } \\
\text { Problems }\end{array}$ & $\begin{array}{c}\text { Pressure } \\
\text { Loss }\end{array}$ \\
\hline Osborne Mine thickened tailings & $65-78 \%$ & Turbulent & $2 \mathrm{~mm}$ & No & Low \\
Stab-flo coal transport & $61 \%$ & Laminar & 0.5 & Yes & Low \\
Limestone pipeline & $56-60 \%$ & Laminar & $0.2-0.3$ & Yes & Low \\
Paste backfill systems & $75-80 \%$ & Laminar & $0.2-0.5$ & Varies & High \\
Kimberley CTP & $50-55 \%$ & Laminar & $1-1.6$ & No & High \\
Chinalco $^{*}$ & - & Laminar & - & - & Moderate \\
Esperanza $^{*}$ & - & Laminar & - & - & Moderate \\
\hline
\end{tabular}

${ }^{*}$ The system has not been commissioned, and construction data is not yet available.

Firstly, the material pumped at Mt Osborne Mine behaves as a settling slurry. Although classified as a high density thickened tailings disposal facility, the material has a low fines fraction and is not non-Newtonian.

Pipe loop data presented by McPhail et al. (2004) in Figure 6 showed typical settling slurry behaviour. The flow is turbulent, and there is a minimum velocity at which this material must be pumped to prevent settling. Observation of this type of flow at low velocities in slurry pipe test facility will clearly show stationary or sliding particles on the pipeline invert.

Systems designed to operate in turbulent flow, such as Mt Osborne, have seemingly fewer problems than those operating in laminar flow. Criteria for successful operation of settling slurries in turbulent flow are relatively straightforward - the slurry velocity must be greater than the slurry deposit velocity by a suitable safety margin. By ensuring that a minimum flow rate is always maintained the risk of settling is minimised, regardless of pipeline diameter or pressure gradient. 


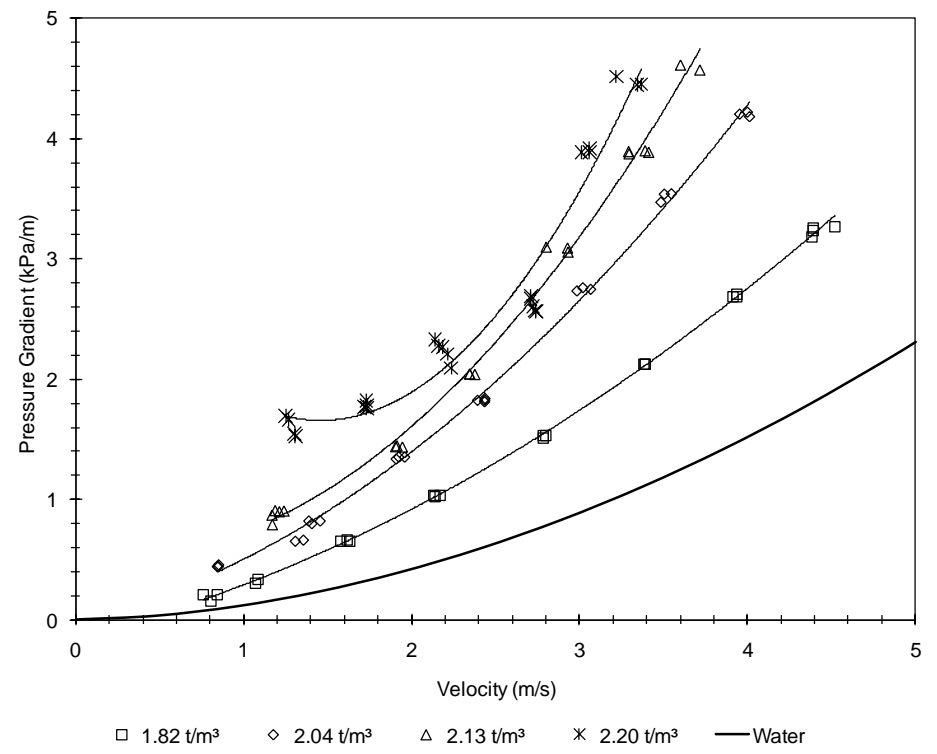

Figure 6 Settling slurry data recorded in pipe loop tests (McPhail et al., 2004)

Non-Newtonian slurries are deceptively complex, as seen by the early experiences with stab-flo and the operation of the limestone slurry pipelines. The test work done for the Belovo-Novosibirsk coal pipeline comprised re-circulating slurry pipe loop tests conducted in $200 \mathrm{~m}$ long $200 \mathrm{~mm}$ diameter pipelines. This work showed that the material could easily be pumped. The measured flow curves for non-Newtonian slurries that have a settled bed are similar to those that do not, and unless direct measurement or observation of a settled bed is made, it is not easy to identify the presence of a settled bed. In this case, any solids that were deposited on the pipeline invert and transported as a sliding bed would have been re-suspended in the centrifugal pump.

The limestone pipelines that operated in a laminar flow also showed a gradual increase in pressure gradient with time due to a settled bed. Recent work by Pullum et al. (2010) shows that for moderate viscosity suspensions particles will begin to settle immediately and that as the flow continues along the pipeline, there will be further stratification. This settling along the pipeline is clearly similar to what was experienced when pumping stab-flo coal mixtures, and in the limestone pipelines.

When we consider the success of paste backfill pumping in laminar flow, we need to investigate the differences between paste backfill and the above mixtures. These essentially are:

- paste backfill is prepared at high solids concentrations using a combination of thickeners or filters

- paste backfill pipelines are relatively small diameter, compared to the larger diameter pipelines used for overland transport

- paste backfill pipeline distances are relatively short, and mostly vertical, compared to long overland systems

- paste backfill pressure losses are exceedingly high, and overland pipelines usually have low pressure gradients.

Solids in a pipeline will settle to their natural solids concentration on the pipe invert, which is called the freely settled concentration. The higher the solids concentration and the closer to this freely settled solids concentration, the greater the viscosity as the particle interaction increases. Paste backfill is generally dewatered to concentrations greater than the freely settled solids concentration. Once these mixtures are in the pipeline, there is very little ability for these particles to segregate en-masse to the invert. Provided that there are sufficient fine particles in the slurry, these mixtures will continue to flow along the pipeline albeit at high friction pressure losses. 
Paste mixtures that are at high solids concentrations can be transported in laminar flow as the particle segregation is limited by the presence of closely packed particles.

When non-Newtonian slurries are pumped at solids concentration less than the freely settled solids concentration, segregation will occur and the solids on the pipe invert will form a settled bed that is equal to the freely settled solids concentration of the slurry. These are the systems that are more prone to blockage. Work done by Thomas (1979), Gillies et al. (1999) and Pullum (2007) and others suggest that for a specific slurry there is a minimum pipeline pressure gradient needed to transport all the solids in the pipeline. Provided that there is sufficient force across the settled bed, the solids will slide along the invert. This pressure gradient is largely independent of pipeline diameter. Minimum pressure loss requirements of $1.5-2 \mathrm{kPa} / \mathrm{m}$ are quoted, however, this is very dependent on the system conditions.

Figure 7 (Pullum, 2007) shows that as pipe diameter increases, for a constant dry tonnage, the expected pressure loss for a homogenous flow will decrease as the slurry solids concentration decreases. If the flow is stratified, then this is clearly not the case, and as pipe diameter increases the pressure gradient is more or less constant as the solids settle on the pipe invert and are transported as a sliding bed.

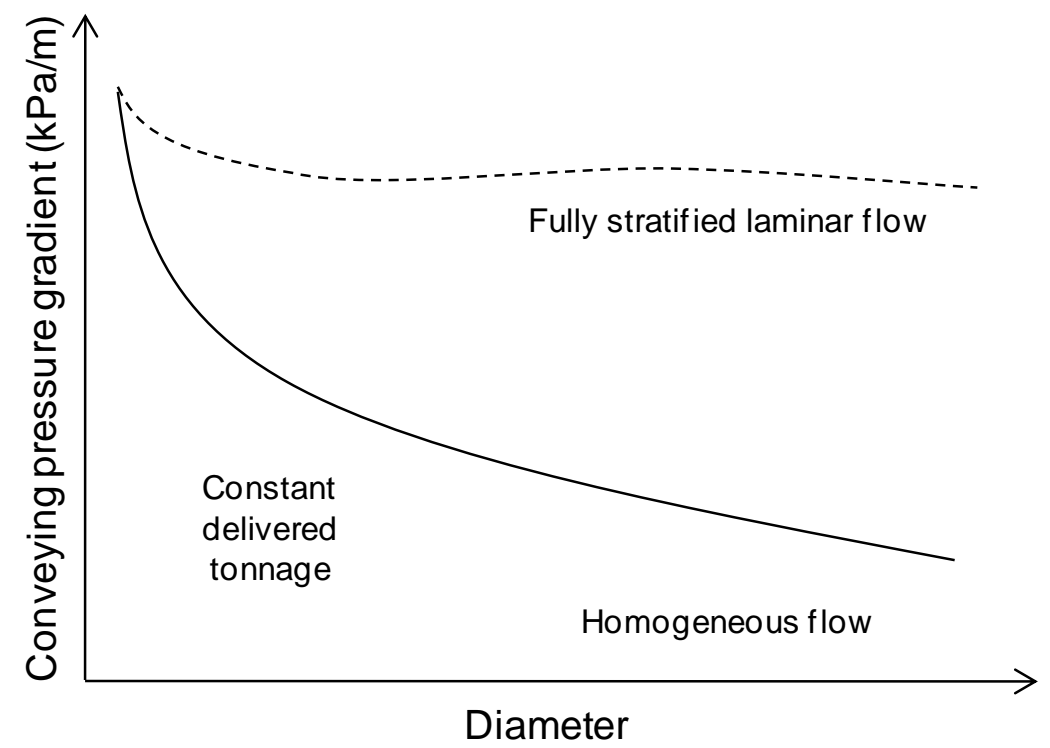

Figure 7 Pressure gradient for stratified and homogeneous laminar flow at a constant mass flow rate, after Pullum (2007)

Another reason why paste backfill systems work is that pipeline diameters are often small, less than $150 \mathrm{~mm}$, and pressure gradients are therefore high. This high friction loss can be overcome by the available gravity head. Slurry that has been tested in a small diameter pipeline may not block as the pressure gradient is high, however, in a larger diameter pipeline transporting the identical slurry, settling may well occur.

Once a particle settles on the pipeline invert, there is no mechanism within turbulent flow to re-suspend these particles (one definition of laminar flow is that streamlines are parallel). The particles remain stationary on the invert until either there is a sufficiently large pressure gradient for the bed to slide, or the flow regime becomes turbulent. For the flow regime to become turbulent the flow rate must be increased, or the solids concentration decreased to reduce viscosity to the point at which the laminar to turbulent transition is below the slurry velocity. Alternately as the settled bed height increases, the flow area reduces, and the flow becomes turbulent and then erodes a portion of the bed, until the area is such that the flow becomes laminar again.

If we examine the paste disposal at De Beers Kimberley CTP project, the system is designed to transport stratified laminar flow slurry. The maximum pump discharge pressure of $12 \mathrm{MPa}$ to transport slurry $5.5 \mathrm{~km}$ provides for a pressure gradient of up to $2.2 \mathrm{kPa} / \mathrm{m}$. This would only occur for the very viscous clay scenarios with yield stress greater than $150 \mathrm{~Pa}$, however, when dilute material is pumped and stratification develops, there is sufficient pressure to move this material as a sliding bed. 


\subsection{Pipeline design implications}

\subsubsection{Data interpretation and modelling}

The majority of design data is obtained from rotational viscometer tests, and occasionally pipeline loop data. Assuming the samples are fully representative and prepared and that corrected rheograms and pipe loop data is obtained, the interpretation of the data needs to be done carefully. An important aspect is the effect of shear on flocculated materials. It is common for these materials to be shear dependent until the floc structure has been dissipated due to shear in transit. Samples tested in the laboratory may not have the same shear history as the full size plant.

If laminar flow loop data is recorded in a small diameter test loop, there is no indication that this material will not settle out in either a longer loop or a larger pipeline. Figure 8 presents pipe friction loss data measured in vertical up, vertical down and horizontal pipelines of $43.6 \mathrm{~mm}$ diameter, as well as $63.8 \mathrm{~mm}$ and viscometer data recorded in a $10 \mathrm{~mm}$ tube viscometer and a rotational viscometer. All the data is plotted on pseudo shear diagram that is a useful tool to validate laminar flow measurements. On this plot the laminar flow data is generally co-incident for different diameters, indicating that there is no slip at the wall. The yield stress, estimated from the flow curve intercept, is approximately $24 \mathrm{~Pa}$. Comparison to the viscometer data shows good agreement and based on this data set one may assume that the pipe flow of this material can easily be predicted using viscometer data. Compare this to Figure 9 that shows that the same slurry at low solids concentrations cannot be well predicted by the viscometer. The small diameters tend to agree well, however, in the larger pipe the measured shear stress values are considerably greater. The yield stress varies from 6 and $12 \mathrm{~Pa}$ depending on the data used, and the implications for pump selection are obvious.

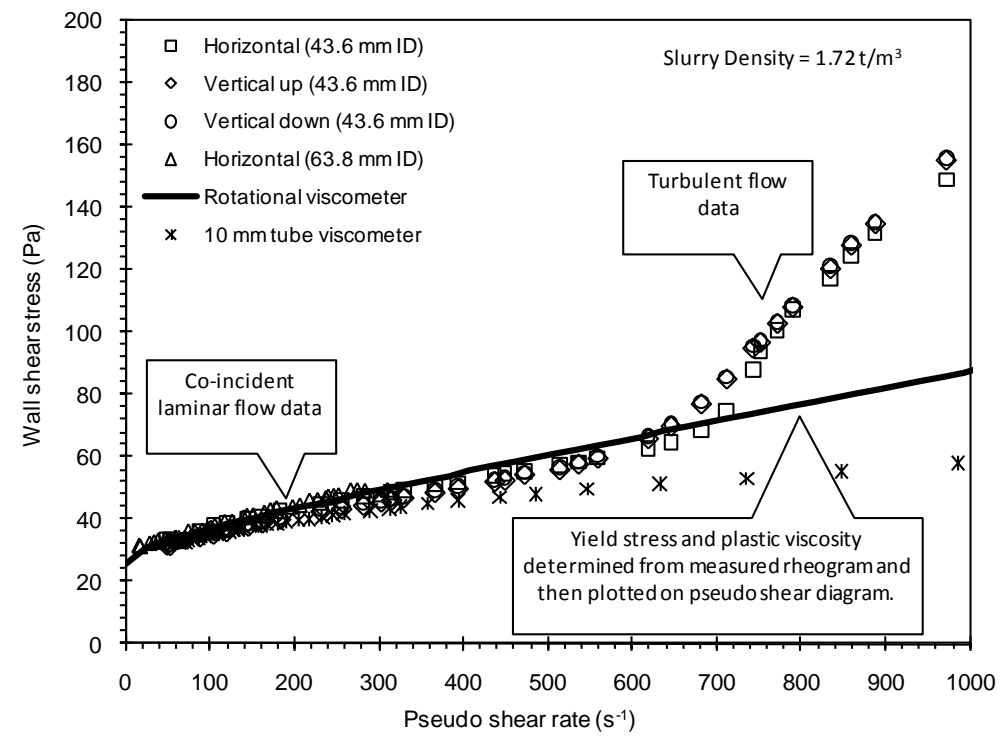

Figure 8 Comparison of data measured in several small diameters and measured in a rotational viscometer at a high solids concentration 


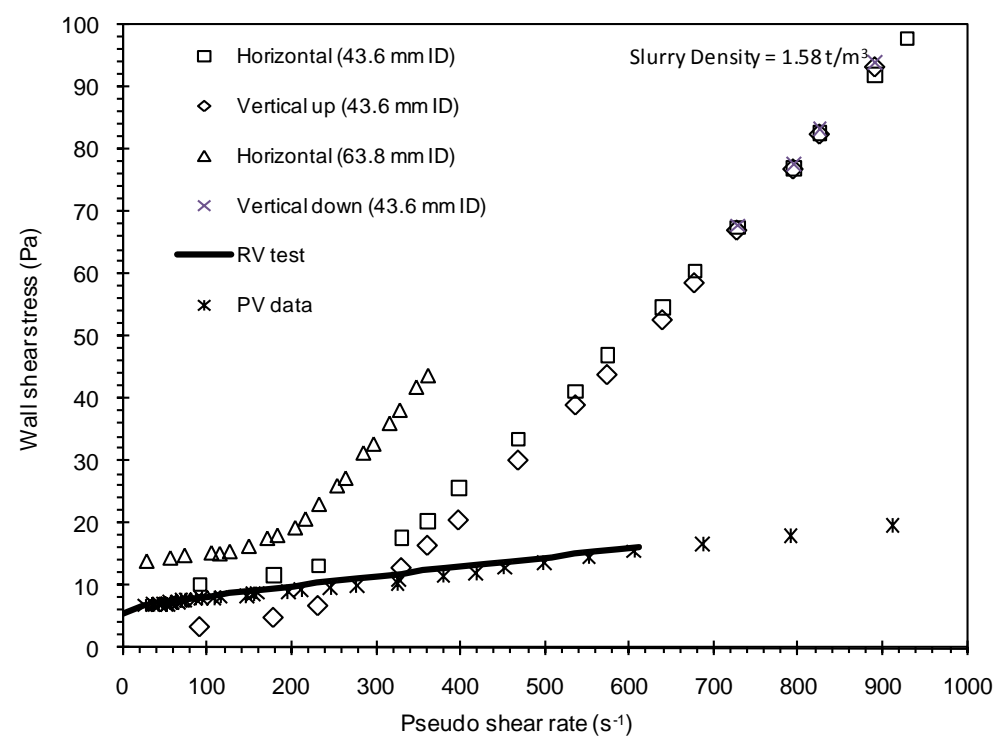

Figure 9 Comparison of data measured in small diameters and measured in a rotational viscometer at a low solids concentration

Because laminar settling occurs in pipe flow it is important that the interpretation of viscometer data is done with caution when used for pipeline design. For a pipeline of any reasonable size and distance, laminar flow settling can have significant cost implications if not accounted for.

\subsubsection{Dealing with laminar flow settling}

We now know that to transport a viscous material successfully in a pipeline, there are several ways in which it is possible:

- The flow should be turbulent if possible, although in practical terms this is unlikely for viscous materials with a yield stress greater than $40 \mathrm{~Pa}$ for most typical pipeline diameters (Paterson, 2006).

- If the flow is laminar, a minimum pressure loss is needed that is sufficient to move a settled bed.

- Solids concentration should be high, in excess of the freely settled bed packing concentration. In this case pressure gradients are likely to be higher than that required to move a settled bed.

If these conditions cannot be met, then the risk of settlement and blockage in the pipeline is high. From a pipeline design perspective, we need to ensure the following when designing a non-Newtonian slurry system:

- The slurry preparation process must be rigorously controlled so that the slurry being pumped meets the criteria for:

- turbulent flow that can be transported above the laminar to turbulent transition velocity, or

- viscous material that has a sufficiently high yield stress, when sheared, to provide a pipeline friction loss pressure gradient that will enable the solids to move as a sliding settled bed.

- If the material cannot be transported in turbulent flow, and laminar flow with a pressure loss less than that required to move the settled bed is inevitable, then the control system must allow for:

- monitoring of a rise in pump discharge pressure with time as a result of settlement,

- flushing capacity to ensure that the solids can be flushed from the system in turbulent flow to remove a settled bed,

○ provision of sufficient installed pump power to generate additional head and flow requirements for flushing, 
- diverting of diluted pipeline discharge away from the disposal area to prevent erosion of the deposition site,

$\circ$ pigging the pipeline if the material is cementitious, such as fly ash or cemented paste fill.

\section{Conclusions}

It has taken many years for high density pumping to reach the current level of development yet in spite of this there is a slow acceptance in the mining industry for using high density paste and thickened tailings for surface disposal.

Many mistakes were made when designing overland pipelines to operate in laminar flow, most notably the Belovo-Novosibirsk stab-flo coal pipeline, and the reasons for these failures are well documented.

The success of pumping high concentration paste backfills underground led many to believe that the same technology would easily be adaptable to surface disposal. However, the reasons for the success of paste backfill turned out to be the hurdles for surface pumping of the same material. Pumping viscous materials in small diameters when energy and power is not a concern, as in a backfill operation, turned out to be very different when attempting to pump the same material in larger diameter pipelines at high pressures.

Several pioneering projects proved that pumping high density material for surface disposal can be done reliably, provided certain criteria are met to prevent laminar flow settling. Such projects paved the way for some of the large tonnage systems being planned, such as Esperanza and Chinalco Mines, which will be the new proving grounds for high volume pumping of viscous materials.

As the demand to pump viscous materials increases, so the flow capacity of high pressure positive displacement pumps has increased in tandem, with the leading suppliers now capable of providing pumps with several megawatts of power each. This means fewer pumps are needed, and will enable the further adoption of the technology.

The issues associated with laminar flow settling are now better understood and by proper measurement of the flow properties in rotational viscometer and slurry pipe test loops it is possible to better estimate the required pipeline pressure gradients. Understanding such issues means that adequate system controls and procedures can be implemented to ensure successful pumping of thickened and paste tailings in long overland pipelines.

The following quote, by Ed Wasp who designed the Black Mesa coal slurry pipeline in the 1960s, is particularly apt when dealing with high concentration flows, and it remains as true today as when first quoted:

"The conviction was that the key to the design of slurry systems which would operate reliably lay, not in the selection of exotic materials or the design of special equipment, but in the understanding and control of the slurry environment." Wasp (1999)

\section{References}

Boger, D., Scales, P.J. and Sofra, F. (2002) Section 3: Rheological concepts, in Paste and Thickened Tailings - A Guide, R.J. Jewell, A.B. Fourie and E.R. Lord (eds), Australian Centre for Geomechanics, Perth, pp. $23-34$.

Cooke, R. (2002) Laminar Flow Settling: The Potential for Unexpected Problems, in Proceedings 15th International Conference on Slurry Handling and Pipeline Transport, Hydrotransport 15, Canada, June 2002.

Cowper, N.T., Sobata, J. and Thomas, A.D. (2010) A technical comparison of coal pipeline options, Hydrotransport 18, BHRA, Rio de Janeiro, Brazil.

Doucet, J. and Paradis, R. (2010) Thickening/mud stacking technology - an environmental approach to residue management, in Proceedings 13th International Seminar on Paste and Thickened Tailings (Paste2010), R.J. in Proceedings 13th International Seminar on Paste and Thickened Tailings (Paste2010), R.J. Jewell and A.B. Fourie (eds), 3-6 May 2010, Toronto, Canada, Australian Centre for Geomechanics, Perth, pp. 3-22.

Duckworth, R.A. and Pullum, L. (1983) The hydraulic transport of coarse coal at high solids concentrations, CSIRO Division of Mineral Engineering, Australia.

Elliott, D.E. and Gliddon, B.J. (1970) Hydraulic transport of coal at high concentrations, in Proceedings First International Conference on the Hydraulic Transport of Solids in Pipes, Hydrotransport 1, BHRA.

Fehrsen, M., Keen, M. and Cooke, R. (2007) Boulby Mine Backfill System: Operational Experience, Minefill 2007, Canada. 
Gillies, R.G., Hill, K.B., McKibben, M.J. and Shook, C.A. (1999) Solids transport by laminar Newtonian flows, Journal of Powder Technology.

Houman, J. and Johnson, G.B. (2003) Commissioning and Operation of the Paste Thickening Farm at Kimberley Combined Treatment Plant, in Proceedings International Seminar on Paste and Thickened Tailings (Paste 2003), 14-16 May 2003, Melbourne, Australia, Australian Centre for Geomechanics, Perth,, Section 12.

Johnson, G.B. and Vietti, A.J. (2003) The Design of a Co-Thickened Slimes Disposal System for Kimberley CTP, in Proceedings International Seminar on Paste and Thickened Tailings (Paste 2003), 14-16 May 2003, Melbourne, Australia, Australian Centre for Geomechanics, Perth, Section 11.

Lawler, H.L., Pertuit, P., Tennant, J.D. and Cowper, N.T. (1978) Application of stabilised slurry concepts of pipeline transportation of large particle coal, in Proceedings 3rd International Technical Conference of Slurry Transportation.

Luppnow, D. and Moreno, J. (2009) Control and management of thickened tailings beach - a simplified approach, in Proceedings 12th International Seminar on Paste and Thickened Tailings (Paste09), R.J. Jewell, A.B. Fourie, S. Barrera, J. Wiertz (eds), 21-24 April 2009, Viña Del Mar, Chile, Gecamin Limited, Santiago, Australian Centre for Geomechanics, Perth, pp. 245-250.

McPhail, G.I. and Brent, C. (2007) Osborne high density discharge - An update from 2004, in Proceedings Tenth International Seminar on Paste and Thickened Tailings (Paste07), A.B. Fourie and R.J. Jewell (eds), 13-15 March 2007, Perth, Australia, Australian Centre for Geomechanics, Perth, pp. 339-350.

McPhail, G.I., Noble, A., Papagoergiou, G. and Wilkinson, D. (2004) Developments and implementation of thickened tailings discharge at Osborne Mine, Australia, in Proceedings International Seminar on Paste and Thickened Tailings (Paste 2004), 31 March - 2 April 2004, Cape Town, South Africa.

Pashias, N., Boger, D.V., Summers, J. and Glenister, D.J. (1996) A fifty cent rheomoter for yield stress measurement, Journal of Rheology, Vol. 40(6), pp. 1179-1189.

Paterson, A.J.C. (2006) Rheology and Thickening, in Proceedings Ninth International Seminar on Paste and Thickened Tailings (Paste06), R.J. in Proceedings Ninth International Seminar on Paste and Thickened Tailings (Paste06), R.J. Jewell, S. Lawson and P. Newman (eds), 3-7 April 2006, Limerick, Ireland, Australian Centre for Geomechanics, Perth, pp. 47-56.

Pullum, L. (2007) Pipelining tailings, pastes and backfill (Keynote Address), in Proceedings Tenth International Seminar on Paste and Thickened Tailings (Paste07), A.B. Fourie and R.J. Jewell (eds), 13-15 March 2007, Perth, Australia, Australian Centre for Geomechanics, Perth, pp. 113-128.

Pullum, L., Graham, L. and Wu, J. (2010) Bed establishment lengths under laminar flow, Hydrotransport 18, BHRA, Rio de Janeiro, Brazil.

Pullum, L., Slatter, P. and Vietti, A.J. (2004) Transport characteristics of stabilised co-disposal tailings line, in Proceedings 12th Transport and Sedimentation of Solids Particles, Prague, Czech Republic.

Rayo, J. and Fuentes, R. (2009) Large tailings disposal - conventional versus paste, in Proceedings 12th International Seminar on Paste and Thickened Tailings (Paste09), R.J. Jewell, A.B. Fourie, S. Barrera, J. Wiertz (eds), 21-24 April 2009, Viña Del Mar, Chile, Gecamin Limited, Santiago, Australian Centre for Geomechanics, Perth, pp. 271-278.

Rogers, E.M. (1962) Diffusion of Innovations, Glencoe: Free Press.

Thomas, A.D. (1979) Pipelining of coarse coal as a stabilized slurry - Another viewpoint, in Proceedings 4th International technical conference on slurry transportation, Las Vegas, USA.

Van Rijswick, R., Kuenen, J., Wilmsen, A. and Sloesen, J. (2010) GLORES, the gateway to piston diaphragm pumps for high volume applications, Hydtransport 18, BHRA, Rio de Janeiro, Brazil.

Wasp, E.J. (1999) Instability of Laminar Flow in Long Distance Pipelines, in Proceedings Rheology in the Minerals Industry II, Kakuka, Hawaii, USA.

Webbstock, D.S., Keen, M.A. and Bradley, R.A. (1993) Backfilling operations at Cooke 3 shaft, Minefill 93, South African Institute of Mining and Metallurgy, Johannesburg, South Africa. 
The pipeline transport of high density slurries - a historical review of past mistakes,

lessons learned and current technologies

A.J.C. Paterson 